\title{
Auditory Neuropathy and Spectrum of Disorder from a Audiological Perspective- A Rare Case Series
}

\author{
Subhashini P Ravichandran, Karthikeyan Ramasamy*, Arun Alexander Sunil Kumar Saxena and Sivaraman \\ Ganesan \\ Department of ENT, Jawaharlal Institute of Postgraduate Medical Education and Research, India
}

Submission: April 06, 2018; Published: April 24, 2018

*Corresponding author: Karthikeyan Ramasamy, Department of ENT, Jawaharlal Institute of Postgraduate Medical Education and Research, India, Tel: +914132296191, Email: guyton2010@gmail.com

\begin{abstract}
An auditory neuropathy is a rare disease in which patient present with inablitiy to understand speech. It is basically the pathology in the hair cell (i.e) transition between the inner and outer hair cell is affected that lead to inability of the patient to comprehend. Pure tone audiometry is normal because the outer cell function is normal and the Brain stem evoked response audiometry is abnormal is the key diagnostic tool. But even with the diagnosis of the disease very limited treatment option are available for these patient. This case series is presented because of its rarity of presentation and diplomacy in the treatment options.
\end{abstract}

\section{Introduction}

Auditory neuropathy is a condition in which the transmission of the auditory signals from the inner ear to the auditory nerve and auditory brainstem is distorted. A typical person with auditory neuropathy has elevated pure tone thresholds, poor speech discrimination scores, absent acoustic reflexes, absent or abnormal auditory brainstem response and present otoacoustic emissions or cochlear microphonics [1]. Pure tone audiometry results usually show bilateral deficits but unilateral hearing loss also can be present [2]. There is a high variability in the configuration of the audiogram. Configuration can be flat, reverse sloping, irregular saw tooth pattern etc [3]. Though the degree of hearing loss is difficult to establish due to their inconsistent responses it can vary from normal to profound hearing loss. Speech perception ability is disproportionate with their PTA results especially in the presence of background competing noise [4].

Absence of middle ear acoustic reflex is a consistent finding in auditory neuropathy spectrum disorder. Otoacoustic emissions are present and also higher in amplitude. Sometimes OAE's may disappear overtime. Auditory brainstem responses are typically absent or abnormal in patients with ANSD. Most of the individual's exhibit cochlear microphonics .Auditory neuropathy can be congenital or acquired. In patients with acquired ANSD the disorder can be attributed to prematurity, hyperbilirubinemia, anoxia, hypoxia, congenital brain abnormalities, perinatal intra cranial hemorrhage, demyelinating conditions. Congenital ANSD is mainly caused by genetic abnormality, which may be either isolated or associated with other syndromes.

About 1 in 10 children identified with permanent childhood hearing loss has auditory neuropathy spectrum disorder (ANSD) [5]. ANSD are extremely heterogeneous in underlying etiology, age and clinical manifestation. The clinical manifestation can also vary greatly in terms of their symptoms as well as the test results [6]. Age of onset can vary from early childhood to adolescence. One study showed that mean age group of ANSD is about 9 years [2].The condition is unpredictable in its time course i.e., can be worsen, same or improve. Prevalence of ANSD is 0.53 in adults with sensory neural hearing loss in Indian population [7]. Current days focus is on the beneficial aspect of hearing aids and performing cochlear implantation in treating the above patients.

\section{Objective of the study}

Retrospective analysis of patients with auditory neuropathy spectrum disorder and their response to hearing aids.

\section{Materials and methods}

The medical records of the patients who presented with sensory neural hearing loss, absent or severely abnormal ABR and presence of DPOAE had been taken for the study. Duration of the study was one year. Total of 10 patients were found. Nine were female and one was male with the age range of 13 to 31 


\section{Global Journal of Otolaryngology}

years. (Table $1 \& 2$ ) shows the data of the patients. Pure tone audiometry was done for all the patients using GSI 61 audiometer. Pure tone thresholds for air conduction and bone conduction were obtained for the frequencies from $250 \mathrm{~Hz}$ to $8000 \mathrm{~Hz}$ and $250 \mathrm{~Hz}$ to $4000 \mathrm{~Hz}$ respectively. Pure tone average was calculated for the frequencies 500, $1000 \& 2000 \mathrm{~Hz}$. Tympanometry was carried out at $226 \mathrm{~Hz}$ probe tone frequency by using Madsen zodiac 901. Ipsilateral and contralateral acoustic reflex were measured for frequencies 500,1000, $2000 \mathrm{~Hz}$ respectively. DPOAE was carried out by using GSI Audera. A ratio of 1.2 between $\mathrm{f} 1$ and $\mathrm{f} 2$ was used to elicit DPOAE. The intensity levels were $65 \mathrm{~dB}$ SPL for L1 and $55 \mathrm{~dB}$ SPL for L2. The amplitude and signal to noise ratio for the frequencies $500 \mathrm{~Hz}$ to $8000 \mathrm{~Hz}$ were obtained. A signal to noise ratio of $6 \mathrm{~dB}$ or above was considered as a criteria for present OAE. Auditory Brainstem Response was recorded in single electrode configuration by using GSI Audera. Click stimuli presented monaurally at rates of 21.1 per second at an intensity of $90 \mathrm{dBnHL}$. Recording consisted of one run of rarefaction, one run of condensation. Control run was done in patients with suspecting cochlear microphonics.

Table 1: Demographic details and results of pure tone audiometry.

\begin{tabular}{|c|c|c|c|c|c|}
\hline \multirow{2}{*}{$\begin{array}{l}\text { Patient } \\
\text { Number }\end{array}$} & \multirow[t]{2}{*}{ Age } & \multirow[t]{2}{*}{ Gender } & \multirow{2}{*}{$\begin{array}{c}\text { Configuration of } \\
\text { PTA }\end{array}$} & \multicolumn{2}{|c|}{ Degree of $\mathrm{HL}$} \\
\hline & & & & Right & Left \\
\hline 1 & 13 & Female & Saw toothed & Mild & Mild \\
\hline 2 & 15 & Female & Saw toothed & Moderate & Profound \\
\hline 3 & 15 & Male & High sloping & Moderate & Mild \\
\hline 4 & 17 & Female & Saw toothed & Mild & Moderately severe \\
\hline 5 & 17 & Female & High sloping & Moderate & Moderate \\
\hline 6 & 27 & Female & Saw toothed & Minimal & Minimal \\
\hline 7 & 21 & Female & Flat & Mild & Mild \\
\hline 8 & 17 & Female & Saw toothed & Moderate & Moderate \\
\hline 9 & 27 & Female & Saw toothed & Mild & Mild \\
\hline 10 & 31 & Female & - & - & - \\
\hline
\end{tabular}

Table 2: Audiometric test battery of the subjects.

\begin{tabular}{|c|c|c|c|c|c|c|c|c|c|c|c|c|}
\hline $\begin{array}{c}\text { Case } \\
\text { no }\end{array}$ & \multicolumn{2}{|c|}{$\begin{array}{l}\text { Pure Tone } \\
\text { Audiometry }\end{array}$} & \multicolumn{2}{|c|}{ Impedance } & \multicolumn{2}{|c|}{$\begin{array}{l}\text { Otoacoustic } \\
\text { emissions }\end{array}$} & \multicolumn{2}{|c|}{$\begin{array}{c}\text { Cochlear } \\
\text { Microphonics }\end{array}$} & \multicolumn{2}{|c|}{$\begin{array}{c}\text { Auditory } \\
\text { brainstem } \\
\text { reflexes }\end{array}$} & \multicolumn{2}{|c|}{ Acoustic reflexes } \\
\hline 1 & 38.5 & 35 & A & A & Present & Absent & Absent & Absent & Absent & Absent & Absent & Absent \\
\hline 2 & 55 & 90 & A & A & Present & Absent & Absent & Absent & Absent & Absent & Absent & Absent \\
\hline 3 & 53.3 & 30 & A & A & Present & Present & Present & Present & Absent & Absent & Absent & Absent \\
\hline 4 & 35 & 65 & A & A & Present & Present & Absent & Absent & Absent & Absent & Absent & Absent \\
\hline 5 & 45 & 45 & A & A & Present & Present & Absent & Absent & Absent & Absent & Absent & Absent \\
\hline 6 & 18.3 & 25 & A & A & Present & Present & Absent & Absent & Absent & Absent & Absent & Absent \\
\hline 7 & 33.3 & 30 & A & A & Present & Present & Absent & Absent & Absent & Absent & Absent & Absent \\
\hline 8 & 58.3 & 51.6 & A & A & Present & Present & Absent & Absent & Absent & Absent & Absent & Absent \\
\hline 9 & 20 & 23 & A & A & Present & Present & Absent & Absent & Absent & Absent & Absent & Absent \\
\hline 10 & $\begin{array}{c}\text { Inconsis } \\
\text { tent }\end{array}$ & $\begin{array}{c}\text { Inconsis } \\
\text { tent }\end{array}$ & A & A & Present & Present & Absent & Absent & Absent & Absent & Absent & Absent \\
\hline
\end{tabular}

\section{Discussion}

Hearing loss was bilateral in all the ten patients. The degree of hearing loss ranged from mild to profound. Six patients were having bilateral symmetrical hearing loss and in the remaining hearing loss were asymmetrical. In the present study, six patients had saw toothed audiometric configuration, two were high sloping, one was flat and the remaining one with inconsistent responses. All the patients had 'A' type tympanogram with absent acoustic reflexes bilaterally. This finding is consistent with the literature. Distortion product otoacoustic emissions were present in all the patients except for the left ear of the patient 2. This shows the involvement of outer hair cell. The degree of hearing loss was profound for the subject.

The results of DPOAE show that it can be used as a reliable tool for the assessment of ANSD. While in our study only one subject we could observe cochlear microphonics. But this finding is contradicting to the literature. This can be due to the procedural variations. Cochlear microphonics can diminish 
over time this may be the reason for absence of cochlear microphonics. Auditory Brainstem Responses and stapedial reflexes were absent in all patients. This finding is consistent with the literature. Pure Tone Average of the participant one showed bilateral mild sensory neural hearing loss. Otoacoustic emissions were present in the right ear, but absent emissions were observed at high frequencies for the left ear.

Case two had moderate sensory neural hearing loss in the right ear and profound hearing loss in the left ear. Otoacoustic emissions present in the right ear and absent for the left ear. Absent otoacoustic emission may be due to the advancement of the disease. Case three audiogram reveals moderate sensory neural hearing loss to the right ear and mild sensory neural hearing loss to the left ear. OAE was present in both the ears. Case four had mild sensory neural hearing loss in the right ear and moderately severe sensory neural hearing loss in the left ear. Bilateral OAEs were present. Bilateral moderate sensory neural hearing loss was seen in case five. OAEs were present bilaterally. Case six had bilateral minimal sensory neural hearing loss, bilateral OAE was present case seven mild sensory neural hearing loss bilateral OAE was present case eight moderate sensory neural hearing loss bilateral OAE was present case nine minimal sensory neural hearing loss bilateral OAE was present.

These findings were consistent with the literature. Case 10 had inconsistent responses with pure tone audiometry with otoacoustic emissions present bilaterally. The use of electrophysiological assessment is very important in the diagnosis of auditory neuropathy spectrum disorder. All patients in our study had under gone hearing aid trial. And patient who should Improvement in hearing in trial where given hearing aid. A prospective longitudinal study by Walker E et al [8] compares children with auditory neuropathy spectrum disorder (ANSD) and sensorineural hearing loss and proves that hearing aids improve language skills and functional outcomes in patients with ANSD as per the American Academy of Audiology Pediatric Amplification Guidelines.

\section{Conclusion}

The clinical manifestation of auditory neuropathy varies greatly between patients depends on the aetiology. It can be diagnosed by taking detailed case history and administering audiological test battery which includes ABR, OAE and acoustic reflex. Hearing aids will benefit most of the patients with moderate to profound hearing loss. Further studies should aim at comparing the benefit of cochlear implantation to hearing aid in terms of hearing benefit, speech production, speech perception and language outcomes.

\section{References}

1. Starr A, Picton TW, Sininger Y, Hood LJ, Berlin CI (1996) Auditory Neuropathy: A new perspective on hearing disorders. Brain 119(3): 741753.

2. Buchman CA, Roush PA, Teagle HF, Brown CJ, Zdanski CJ, et al. (2006) Auditory neuropathy characteristics in children with cochlear nerve deficiency. Ear Hear 27(4): 399-408.

3. Starr A, Sininger Y, Pratt H (2000) The varieties of auditory neuropathy. J Basic Clin Physiol Pharmacol 11(3): 215-230.

4. Zeng FG, Liu S (2006) Speech perception in individuals with auditory neuropathy. J Speech Lang Hear Res 49(2): 367-380.

5. Rance G, Beer DE, Cone-Wesson B, Shepherd RK, Dowell RC, et al. (1999) Clinical findings for a group of infants and young children with auditory neuropathy. Ear and Hear 20(3): 238-252.

6. Manchaiah VKC, Zhao F, Danesh AA, Duprey R (2011) The genetic basis of auditory neuropathy spectrum disorder (ANSD). Int J Pediatr Otorhinolaryngol 75(2): 151-158.

7. Kumar UA, Jayaram MM (2006) Prevalence and audiological characteristics in individuals with auditory neuropathy/dys synchrony. Int J Audiol 45(6): 360-366.

8. Walker E, Mc Creery R, Spratford M, Roush P (2016) Children with Auditory Neuropathy Spectrum Disorder Fitted with Hearing Aids Applying the American Academy of Audiology Pediatric Amplification Guideline: Current Practice and Outcomes. J Am Acad Audiol 27(3): 204-218.

\section{Your next submission with Juniper Publishers will reach you the below assets}

- Quality Editorial service

- Swift Peer Review

- Reprints availability

- E-prints Service

- Manuscript Podcast for convenient understanding

- Global attainment for your research

- Manuscript accessibility in different formats

( Pdf, E-pub, Full Text, Audio)

- Unceasing customer service

Track the below URL for one-step submission https://juniperpublishers.com/online-submission.php 